\title{
DNA Repair as an Emerging Target for COPD-Lung Cancer Overlap Catherine R. Sears ${ }^{1}$
}

${ }^{1}$ Division of Pulmonary, Critical Care, Sleep and Occupational Medicine, Department of Medicine, Indiana University, Indianapolis, Indiana; The Richard L. Roudebush Veterans Affairs Medical Center, Indianapolis, IN, 46202, U.S.A.

Corresponding Author.

Catherine R. Sears, M.D.

980 W. Walnut Street

Walther Hall, C400

Indianapolis, IN 46202

tel: 317-278-0413. fax: 317-278-7030

crufatto@iu.edu

Abstract length: 151

Article length (excluding tables and figures): 3,988

Number of Figures: 1 Tables: 1

Conflict of Interest Declaration: The author of this publication has no conflicts of interest to declare.

This publication is supported in part by funding from the American Cancer Society (128511-MRSG-15-163-01DMC) and the Showalter Research Foundation.

This is the author's manuscript of the article published in final edited form as:

Sears, C. R. (2019). DNA repair as an emerging target for COPD-lung cancer overlap. Respiratory Investigation, 57(2),

111-121. https://doi.org/10.1016/j.resinv.2018.11.005 


\section{Abstract}

Cigarette smoking is the leading cause of lung cancer and chronic obstructive pulmonary disease (COPD).

Many of the detrimental effects of cigarette smoke have been attributed to the development of DNA damage, either directly from chemicals contained in cigarette smoke or as a product of cigarette smoke-induced inflammation and oxidative stress. In this review, we discuss the environmental, epidemiological, and physiological links between COPD and lung cancer and the likely role of DNA damage and repair in COPD and lung cancer development. We explore alterations in DNA damage repair by DNA repair proteins and pathways. We discuss emerging data supporting a key role for the DNA repair protein, xeroderma pigmentosum group $\mathrm{C}$ (XPC), in cigarette smoke-induced COPD and early lung cancer development. Understanding the interplay between cigarette smoke, DNA damage repair, COPD, and lung cancer may lead to prognostic tools and new, potentially targetable, pathways for lung cancer prevention and treatment.

Keywords: emphysema, cigarette smoke, mutations, oxidative stress, nucleotide excision repair

*Abbreviations- 8-OHdG: 8-hydroxy-2'-deoxyguanosine, APE1: apurinic/apyrimidinic endonuclease 1, BER: base excision repair, COPD: chronic obstructive pulmonary disease, CUL4A: Cullin-4A, dNTP: deoxyribonucleotide triphosphate, DSBs: double strand DNA breaks, ERCC1: ERCC excision repair 1, endonuclease non-catalytic subunit, FEN1: Flap endonuclease 1, FEV1: forced expiratory volume in one second, GOLD: Global Initiative for Chronic Obstructive Lung Disease, HRR: homologous recombination repair, KRas: Kirsten rat sarcoma 2 viral oncogene homolog, MGMT: O(6)-methylguanine-DNAmethyltransferase, MLH1: MutL protein homolog 1, MMR: mismatch repair, MPG: methyl purine DNA glycosylase, MSH2: MutS protein homolog 2, MSH6: MutS protein homolog 6, MTH1: MutT homolog 1, MUTYH: mutY homolog (E. coli), NEIL2: Nei-like DNA glycosylase 2, NER: nucleotide excision repair,NHEJ: non-homologous end-joining, NNA: 4-(methylnitrosamino)-4-(3-pyridyl)butanal, NNK: 4-(methylnitrosamino)-1(3-pyridyl)-1-butanone, NNN: N'-nitrosonornicotine, Ogg1: 8-Oxoguanine glycosylase, PAH: polycyclic aromatic hydrocarbon, PBMC: peripheral blood mononuclear cells, PMS2: PMS1 homolog 2, mismatch repair system component, RRMI: ribonucleotide reductase catalytic subunit M1, SSBs: single strand DNA breaks, Trp53: transformation related protein 53, XPC: xeroderma pigmentosum group A, XPC: xeroderma pigmentosum group $\mathrm{C}, \mathrm{XRCC1}$ : X-ray repair cross-complementing protein 1, XRCC3: X-ray repair crosscomplementing protein 3, XRCC4: X-ray repair cross-complementing protein 4 
COPD and Lung Cancer: Links in Exposure and Epidemiology

Chronic obstructive pulmonary disease (COPD) and lung cancer represent a large burden of lung disease worldwide. Lung cancer is the leading cause of cancer-related mortality, estimated to cause more than 1.6 million deaths worldwide per year [1]. COPD is an even larger burden, as it is currently the third-leading cause of death worldwide, causing more than 3.2 million deaths in 2015 [2, 3]. On the surface, COPD and lung cancer are very different diseases. COPD is characterized by two main findings: irreversible expiratory air flow limitations caused by narrowing and inflammation of the small airways (obstructive bronchiolitis) and progressive destruction and enlargement of distal lung tissue (emphysema). These findings are often accompanied by an altered damage response to cigarette smoke, leading to an increase in apoptosis, altered autophagy, and premature senescence [4]. Alternatively, lung cancer is characterized by unchecked cellular proliferation and alterations in the normal response to DNA damage, most characteristically through antiapoptotic and pro-proliferative processes [5]. However, many studies support a clear connection between these two seemingly disparate diseases. The most common causative exposure leading to each of these diseases is tobacco smoke inhalation, particularly through cigarette smoking. However, only a minority of smokers develop COPD or emphysema (10-15\%), indicating that other epigenetic, genetic, and/or environmental factors play a crucial role in their development [6]. While some have speculated that the development of COPD or lung cancer may simply represent two extreme end-results of cigarette smoke exposure, numerous other studies have suggested that COPD and lung cancer share many commonalities.

Cross-sectional and epidemiological studies have identified COPD as a risk factor for lung cancer development, even when corrected for smoking history. Lung cancer is identified as the cause of death in a third of patients with mild-to-moderate COPD: a number disproportionate to the expected number with lung cancer based on smoking alone [7], Furthermore, bronchoscopic biopsies from approximately half of those with COPD ( $56 \%$ of men and $44 \%$ of women) show early cancerous changes in the lung epithelium, ranging from moderate dysplasia to carcinoma in situ [8]. COPD-associated airway obstruction, measured by both spirometric severity score and the decrease in forced expiratory volume in one second (FEV1), is inversely correlated with lung cancer risk. The NHANES database reveals a 3-fold increase in lung cancer in those with mild COPD and a 6-fold greater risk in patients with moderate-to-severe COPD, compared to those with 
normal spirometry results [9]. Cross-sectional analyses of smokers matched for age, gender, and smoking volume have shown a 4- to 6-fold increased risk of lung cancer in patients with COPD, with decreases in FEV1 being inversely proportional to increases in lung cancer risk $[10,11]$. This relationship between COPD severity and lung cancer risk is further supported by the recent prospective study of spirometric data by the NLSTACRIN cohort, showing a linear increase in lung cancer diagnosis with increasing COPD severity, as measured by the GOLD staging system [12]. Carriers for alpha- 1 antitrypsin disease, a hereditary cause of COPD, have approximately twice the risk of lung cancer compared to matched controls, even when adjusted for smoking history and age, thus supporting a smoking-independent link between COPD and lung cancer [13]. In addition to physiological changes, structural changes seen in COPD also appear to increase the risk of lung cancer, with increased alveolar destruction, observed on computed tomography scans, correlating with a higher risk of lung cancer [14-16].

\section{Familial Aggregation, Genetics, and Epigenetics}

Smoking-induced lung cancer and COPD are both characterized by familial aggregation. A family history of lung cancer confers approximately 2.5 -fold increased risk of lung cancer development, when corrected for smoking history [17]. A number of studies have investigated candidate genetic markers and gene variations, which seem to confer an increased susceptibility to lung cancer and COPD. Among these are genes involved in cellular metabolism, damage response mechanisms, immune regulation, protease/anti-protease activity, and DNA repair [6]. More recent studies have highlighted potentially important roles of epigenetic changes, such as DNA methylation, microRNA expression, and histone acetylation, in the link between cigarette smoke, COPD, and lung cancer development [18]. While these links have been described, care should be taken to not apply this uniformly across both diseases. For instance, there may be differences in lung cancer susceptibility based on the predominant COPD features (emphysema or bronchiolitis), which vary from person to person and are characterized by different pathological and physiological findings. Similarly, differences in exposure, cellular mechanisms, and the local environment, lead to differential development of histological sub-types of lung cancer [19], which may not be uniformly linked to COPD risk or development.

Finally, both lung cancer and COPD are diseases characterized not only by chronic cigarette smoke exposure, 
but also by advanced age. Cellular and environmental characteristics of advanced lung aging, such as cellular senescence, impaired telomere maintenance, altered autophagy, proteasome imbalance, chronic inflammation, and impaired oxidant defense, may provide further clues into the COPD-lung cancer overlap [20, 21]. These and additional epidemiological, genetic, and mechanistic links have been covered in other excellent reviews $[6,18]$.

\section{Cigarette Smoke, Pulmonary Inflammation and DNA Damage}

COPD and lung cancer are both characterized by an altered local immune response. An increase in lung macrophages and neutrophils, which is a hallmark of COPD, causes the release of proteases, cytokines and oxidative stress, leading to the destruction of the extracellular matrix, loss of cellular integrity within the alveoli and epithelium, and cell death [4]. Increased inflammation is also observed in lung cancer and the relationship between lung cancer and the surrounding inflammation is crucial to lung cancer development. This inflammation is believed to initially inhibit or limit cancer growth, but then adaptive responses of malignant cells and the surrounding matrix cells lead to an environment in which this inflammation actually serves as a driver of cancer growth and metastasis [5].

Endogenous sources of DNA damage, such as those caused by byproducts of normal cellular metabolism, can cause up to $10^{5}$ DNA lesions per cell per day, and exposure to carcinogens such as cigarette smoke further increases that number [22]. Cigarette smoking causes a wide variety of DNA adducts, which can be found in cancer cells as well as in adjacent "normal" cells in the lungs. These DNA adducts increase with the number of cigarettes smoked (Figure 1). In smokers, non-oxidized DNA lesions number as high as 34 adducts per $10^{8}$ nucleotides, which is more than 10 times the number of lesions found in the DNA of nonsmokers. The number of small modified DNA bases, such as etheno-DNA adducts and oxidized bases, may be even higher [23-25]. Smoking-induced lung cancers are characterized by extreme genomic instability [26, 27]. DNA lesions cause differential activation of DNA damage repair processes depending on the amount and type of DNA damage. This can lead to a number of physiologic outcomes, including activation of DNA repair processes with subsequent repair of the DNA lesions or apoptosis, cell senescence, cell cycle alterations, and/or altered autophagy. In those cells that survive, unrepaired DNA lesions may eventually be repaired by 
less fidelitous repair pathways, leading to deletions, mutations, and translocations, which can eventually lead to cancer [28, 29] (Figure 1). Indeed, the non-cancerous lungs of smokers often reveal characteristic mutations, clonal allelic loss, and altered methylation patterns characteristic of lung cancer [30-32].

Among other potential mechanisms, oxidant stress has been postulated to play an important role in the development of both COPD and lung cancer. Many studies have shown an increase in genomic DNA damage caused by cigarette smoke [33]. This is driven by an increase in free radicals caused directly by side-products of cigarette smoke or by an increase in inflammation within the lung. Oxidized DNA bases are increased in both COPD and lung cancer [34, 35]. An increase in nucleic acid oxidation has been observed in alveolar wall cells in COPD compared to cells from non-COPD lungs, linearly increasing with worsening histologic evidence of emphysema [36]. One of the most studied oxidized bases, 8-hydroxy-2-deoxyguonisine (8-OHdG), is increased by cigarette smoke and is elevated in both COPD and lung cancer [35-37]. Other types of DNA damage caused by reactive oxygen species, including oxidized bases, single strand breaks, and abasic sites, are increased in both diseases $[34-36,38,39]$. Other exposures associated with COPD, such as biomass, also lead to an increase in oxidative stress and DNA damage, but their levels appear higher in cigarette smoke-induced COPD [40]. However, the increase in DNA damage is unlikely to be due to cigarette smoke alone, as the lungs of patients with COPD have higher levels of DNA damage, including double-strand breaks, than the lungs of smokers and non-smokers without COPD [40,41]. COPD patients have a higher frequency of somatic mutations and loss of heterozygosity and higher levels of microsatellite instability [38, 42-44]. In COPD patients, higher levels of oxidative DNA damage are found clustered in functionally significant sequences, including the hypoxic response element of the vascular endothelial growth factor (VEGF) promoter [45]. This suggests that oxidative DNA damage plays a role beyond random increases in DNA damage, leading to subsequent cell death by apoptosis.

\section{DNA Repair in Lung Cancer}

Altered DNA repair has long been established as a hallmark of cancer. Indeed, heterozygous mutations in a number of DNA repair proteins have been directly linked to hereditary forms of cancer development. Most notably, mutations in mismatch repair genes (including $M L H 1, M S H 2, M S H 6$, and PMS2) are seen in 
hereditary nonpolyposis colorectal cancer and mutations in homologous recombination genes (BRCA1 and $B R C A 2)$ are seen in hereditary breast and ovarian cancers $[46,47]$. The discovery of EGFR gene mutations associated with a minority of lung cancers in non-smokers, revolutionized the thinking of lung cancer as a potentially targetable malignancy [48]. In spite of these very clear examples, most lung cancers found in smokers are not associated with a clear heritable mutation. However, there is evidence that those with impaired DNA repair capacity are at an increased risk for lung cancer development and that altered DNA repair processes likely play an important role in the development of sporadic lung cancers [49].

A number of studies have implicated altered DNA repair pathways in lung cancer development. Several DNA repair pathways are highly involved in the repair of cigarette smoke-induced DNA damage and many of them have overlapping roles. The nucleotide excision repair pathway (NER) is primarily involved in the repair of bulky DNA lesions that distort the DNA helical structure. The base excision repair pathway (BER) is involved in the repair of small base modifications, including oxidized and alkylated bases, depurination/depyrimidination and many single strand breaks. DNA mismatch repair (MMR) is involved in repairing errors in complementary strand bases (misincorporated bases) and deletions. Finally, the homologous recombination repair (HRR) and non-homologous end-joining (NHEJ) pathways repair the highly deleterious double-strand breaks that can occur as a side-effect of cigarette smoke inflammation, DNA damage, or replication stress [33, 50] (Figure 1).

Evaluation of the impact of DNA repair proteins on early lung cancer development is complicated by the heterogeneity of the disease. This includes differences in histology, poor understanding of the temporal development of mutations, and the findings that DNA repair protein expression and function may change following treatment with either chemotherapy or radiation $[51,52]$. To evaluate the impact of DNA repair on early lung cancer development, DNA repair pathways have been extensively evaluated in an attempt to discover single nucleotide polymorphisms and expression patterns that may be predictive of lung cancer risk or provide a target for interventions (Table 1). A number of candidate DNA repair genes have been investigated to evaluate their impact on lung cancer risk. Most of these studies have had variable findings and, where an association has been found, only mild impacts on lung cancer risk were detected (Table 1). The variability of these findings may be due to many patient-related or technical factors, including differing ethnicities or other population variations, differential impacts on different lung cancer histologies, smoking status, and patient age. 
More recent studies have evaluated combinations of gene polymorphisms, often taking into consideration smoking status, age, and ethnic group of the study population. These studies have identified some promising prognostic markers of lung cancer development within specific groups [48].

Many recent evaluations have focused on epigenetic changes in lung cancer, with DNA methylation and acetylation being implicated in altering DNA repair protein expression and function [32]. These investigations have included the MMR proteins, MLH1 and MSH2, which are altered by gene promoter methylation in lung cancers $[53,54]$. Altered methylation of another MMR protein, MGMT, also appears to be linked to lung cancer $[55,56]$. A number of studies have used ex vivo DNA repair and DNA repair protein functional assays to evaluate the risk of lung cancer development. Decreased MGMT activity has been observed in cultured fibroblasts from lung cancer patients, although results have been variable in other cell types. However, several functional polymorphisms of MGMT, identified as possible modulators of lung cancer risk, decrease the repair of alkylated DNA lesions in in vitro DNA cleavage assays [57]. Within the BER pathway, decreased glycosylase activity of both APE1 and OGG1 in human peripheral blood mononuclear cells (PBMCs) has been associated with an increased risk of lung cancer development (58-60). Poor repair activity, as measured by an integrated score of OGG1, MPG, and APE1 activity, is also strongly associated with increased lung cancer risk [61]. A functional polymorphism of the BER protein, NEIL2 [R257L], is associated with decreased in vitro BER activity, indicating that this gene variant may play a role in lung cancer development [62]. Interestingly, increased activity of another BER protein, MPG, has been observed in lung cancer patients, implying that a careful balance between DNA damage and repair may be needed to avoid cancer development [63]. A number of studies support an important role for the NER pathway in lung cancer development. Cleavage and host cell reactivation assays performed in human blood PBMCs, correlate decreased NER repair with an increased lung cancer risk [49, 60, 61, 64-69].

Several mouse models with a predisposition to multiple solid-organ tumors, highlight an important, but largely generalized, role of DNA repair in early lung cancer development. Deficiencies in single BER genes (including Ogg1) have been associated with a mild increase in oxidative DNA damage, with further increases seen in combination with the knock-out of other DNA repair proteins [70]. Malignant tumors are observed with advanced age in $\mathrm{Ogg}^{-1-}$ mice which also have other DNA repair proteins (MUTYH and MSH2) knocked out. 
However, these findings were not isolated to the lung, as lung, ovarian, and uterine tumors and lymphomas

were all observed. Combined deficiencies of Ogg1 and Mth1, which is involved in MMR, results in decreased lung tumor development, possibly from exhaustion of the dNTP pool, suggesting the likely importance and complex interplay of multiple DNA repair pathways in lung cancer development [71, 72]. A specific E160D mutation in FEN1, which is involved in BER, has also been shown to increase lung cancer development with age and carcinogen exposure in mice [73]. Deficiency in the MMR protein, MGMT, leads to lung tumor development in mice treated with the alkylating carcinogens, $\mathrm{N}$-nitroso-N-methylurea (NMU) and dimethylnitrosamine (DMN). However, other cancers (thymus and liver) are also observed in this model [57]. Within the NER pathway, lung-specific CUL4A overexpression in mice is associated with an increase in spontaneous lung tumors with age $[74,75]$. However, individual knock-out of other NER proteins shows low penetrance of lung cancer development, but results in accelerated tumor development with carcinogen exposure. Lung cancer development also increases when the individual NER protein knock-out is combined with the knock-out or mutation of other proteins. Of particular interest is the NER protein, XPC, which, unlike other NER proteins, appears to be associated with tumor development primarily in the lung [76-78]. A number of other mouse models have combined deficiencies of DNA repair proteins with highly aggressive conditional and transgenic mouse models of lung cancer, such as those involving KRas and Trp53. Combined with these strong oncogenes and tumor suppressor proteins, many DNA repair proteins show an important synergistic role in lung cancer [79-82]. However, these results must be interpreted with caution, as oncogene-driven mouse models may already show altered interactions with and adaptive alterations in DNA repair processes [83]. The impact of other DNA repair proteins and pathways on lung cancer development has also been investigated (Table 1). Overall, these findings support a mechanism by which lung cancer susceptibility involves a complex interplay of environmental and hereditary factors and in which functional impairment of DNA repair pathways increases lung cancer risk.

\section{DNA Repair in COPD}

Although the direct mechanistic link has not been fully elucidated, the requirement of altered DNA repair for lung cancer development and progression is well established. Less well understood is the role of 
DNA repair in COPD development. Smoking itself increases the number of DNA lesions and smokers with decreased DNA repair may be at an increased risk for lung diseases, including COPD. For instance, lung samples of patients with COPD caused by smoking, show an increase in 8-OHdG (an oxidative stress-induced DNA lesion), similar to that observed in healthy smokers. However, these patients have a lower number of apurinic/apyrimidinic sites, an intermediate in BER, suggesting decreased BER activity in the lungs of COPD patients compared to healthy smokers exposed to similar amounts of cigarette smoke-induced oxidative stress $[34,84]$. Studies have attempted to find candidate genes and single nucleotide polymorphisms responsible for the development of COPD with and without lung cancer. Many of these studies have focused on proteins involved in DNA repair (Table 1). In one such study, five genes showed a strong association with COPD. Three of these genes are involved in glutathione metabolism (oxidative stress regulation), one is involved in DNA repair (ERCC1 in NER), and one is involved in genomic and mitochondrial DNA replication (RRM1) [85]. A recent study reported increased DNA damage and decreased repair in PBMCs from COPD patients with specific variants of XRCC1, OGG1 (both involved in BER), XRCC3, and XRCC4 (both involved in doublestrand break repair through HR and NHEJ, respectively). However, these results were almost certainly confounded by increased cigarette use in the COPD group compared to the controls (86). Polymorphisms of $X P C, X P A$, and XRCC5 (Ku80) genes have been associated with an increased risk of COPD and have also been implicated in cancer development [87-91]. Specific polymorphisms of DNA repair proteins believed to increase COPD risk may not correlate with lung cancer risk, as seen in the analysis performed by deAndrade et al., and may vary by tobacco use and specific alleles analyzed [85, 92].

Impaired DNA double-strand break repair has been implicated as a driver of COPD development. In particular, mutations in Ku80, a protein integral to NHEJ repair of DNA double-strand breaks and encoded by the COPD susceptibility gene, $X R C C 5$, on chromosome $2 \mathrm{q}$, has been implicated as a risk factor in COPD development in both humans and mice $(88,93)$. Decreased levels of Ku80 have been observed in smokers with COPD, who also show the highest levels of oxidative DNA damage (8-OHdG), indicating a potential link between cigarette smoke exposure and decreased DNA repair protein expression [34]. Mouse models lacking the essential NHEJ protein, Ku70 (XRCC6), develop the functional and structural changes of COPD with age and this is associated with an increase in apoptosis [94]. PARP-1 is involved in BER and has targeted 
therapies available. Its activation, as measured by PAR-polymerase positivity and biotinylated-NAD incorporation assays, is increased in peripheral lymphocytes from COPD patients when compared to those from subjects without COPD [95]. Microsatellite instability, often characterized by impaired MMR function, is increased in lung cancer and COPD $[43,96]$. Mutations of MMR proteins, including MLH1, MSH2, and MGMT, appear to occur late in the development of non-small cell lung cancers (NSCLC) and recent studies have highlighted a strong association between promoter methylation of many MMR genes and NSCLC development [53, 55, 97-99]. As tobacco smoking is known to alter DNA methylation, this may represent another important connection between DNA repair, COPD, and lung cancer development.

$X P C, C O P D$, and Lung Cancer

Most of the DNA repair genes implicated as possible drivers of COPD have not been directly linked to lung cancer development. Loss of heterozygosity at chromosome $3 p$ is one of the earliest genetic events in lung cancer development, occurring even in the histologically normal epithelium of smokers $[100,101]$. Many genes commonly mutated in cancer are involved in apoptosis and cell cycle regulation and are located on chromosome 3p. These include FHIT, RASSF1A, and SEMA3B (28). Also located on chromosome $3 p$ is the gene encoding the DNA repair protein, xeroderma pigmentosum group $C(X P C)$. XPC is involved in the recognition and repair of bulky DNA lesions through NER and has, more recently, been implicated in the repair of smaller oxidative DNA lesions (such as 8-OHdG) through the BER pathway [102-105]. Findings of decreased XPC expression in lung adenocarcinomas of mice and humans and in immunohistochemical analysis of human lung squamous cell carcinomas have led to speculation that decreased XPC expression may play an important role in early lung cancer development $[106,107]$. This is further supported by epidemiological studies, which have proposed a link between common XPC polymorphisms and lung cancer development [108-110]. Exposure of C57BI/6 mice to 6 months of cigarette smoke leads to decreased expression of XPC mRNA compared to littermates exposed to ambient air, but no change in the expression of other measured DNA repair proteins involved in the NER and BER pathways [87]. Others have reported that exposure of mice to side stream smoke (up to 16 weeks) decreases expression of the DNA repair proteins, XPC and OGG1, and decreases NER and BER activity [111]. We have recently demonstrated an important 
role of XPC in the prevention of emphysema-like lung disease with aging in mice exposed to chronic cigarette smoke [87]. $\mathrm{Xpc}^{-/-}$mice develop increased lung compliance and alveolar rarefication with age, which is further increased by chronic cigarette smoke exposure [87]. XPC has also been identified as important factor in cancer development, with its best-characterized role in protecting against UV-induced skin cancers [112]. In mice, XPC deficiency is associated not only with UV-induced skin cancer, but also with increased lung tumor development with age and pro-oxidant exposure [77, 103]. XPC deficiency was not associated with an increased risk of other solid organ tumors and the increase in lung tumors appears to be unique to XPC function, rather than the NER pathway in general, since knock-out of XPA, a protein essential to NER, does not lead to an increase in lung tumor development in mice [76]. We have recently found that XPC protects against lung adenocarcinoma development caused by cigarette smoke (" $5+4$ months" as per Witschi et al [113]) and carcinogen exposure in a gene dose-dependent manner (unpublished data). This suggests a mechanism by which loss of a single $X p c$ allele may be sufficient to increase lung cancer risk with cigarette smoke/carcinogen exposure, as has been suggested in skin cancers [107]. Further investigations into the specific mechanisms underlying this risk are ongoing. The mechanism may require impaired DNA repair, altered DNA damage response, and changes in lung inflammation for XPC-COPD-lung cancer development.

\section{Conclusions}

Great progress has been made in understanding the mechanisms underlying the development of COPD and lung cancer. Although COPD has clearly been identified as a risk factor for lung cancer development, our understanding of the mechanisms underlying this connection is incomplete. Altered functions of DNA repair pathways are likely to play a role in this COPD-lung cancer overlap. A greater understanding of the link between DNA damage, chronic inflammation, and DNA repair in COPD and lung cancer will help in risk prediction and the development of improved therapeutic options for these two diseases.

Acknowledgements: The author would like to thank Dr. John Turchi for critical review of this manuscript. 


\section{References}

1. Wong MCS, Lao XQ, Ho KF, Goggins WB, Tse SLA. Incidence and mortality of lung cancer: global trends and association with socioeconomic status. Sci Rep 2017;7(1):14300.

2. Soriano JB, Abajobir AA, Abate KH, Abera SF, Agrawal A, Ahmed MB, et al. Global, regional, and national deaths, prevalence, disability-adjusted life years, and years lived with disability for chronic obstructive pulmonary disease and asthma, 1990-2015: a systematic analysis for the Global Burden of Disease Study 2015. Lancet Respir Med 2017;5(9):691-706.

3. Quaderi SA, Hurst JR. The unmet global burden of COPD. Glob Health Epidemiol Genom. 2018;3:e4.

4. Tuder RM, Petrache I. Pathogenesis of chronic obstructive pulmonary disease. J Clin Invest 2012;122(8):2749-55.

5. Hanahan D, Weinberg RA. Hallmarks of cancer: the next generation. Cell 2011;144(5):646-74.

6. Punturieri A, Szabo E, Croxton TL, Shapiro SD, Dubinett SM. Lung cancer and chronic obstructive pulmonary disease: needs and opportunities for integrated research. J Natl Cancer Inst 2009 Apr;101(8):554-9.

7. McGarvey LP, John M, Anderson JA, Zvarich M, Wise RA, Committee TCE. Ascertainment of causespecific mortality in COPD: operations of the TORCH Clinical Endpoint Committee. Thorax 2007;62(5):411-5.

8. Lam S, leRiche JC, Zheng Y, Coldman A, MacAulay C, Hawk E, et al. Sex-Related Differences in Bronchial Epithelial Changes Associated with Tobacco Smoking. J Natl Cancer Inst 1999;91(8):691-6.

9. Mannino DM, Buist AS, Petty TL, Enright PL, Redd SC. Lung function and mortality in the United States: data from the First National Health and Nutrition Examination Survey follow up study. Thorax 2003;58:388-93.

10. Tockman MS, Anthonisen NR, Wright EC, Donithan MG, Group TIPPBT, Cancer TJHLPftEDoL. Airways Obstruction and the Risk for Lung Cancer. Ann Intern Med 1987;106:512-8.

11. Islam SS, Schottenfeld D. Declining FEV1 and Chronic Productive Cough in Cigarette Smokers: A 25Year Prospective Study of Lung Cancer Incidence in Tecumseh, Michigan. Cancer Epidemiol Biomarkers Prev 1994;3:289-98.

12. Hopkins RJ, Duan F, Chiles C, Greco EM, Gamble GD, Aberle D, et al. Reduced Expiratory Flow Rate among Heavy Smokers Increases Lung Cancer Risk: Results from the NLST-ACRIN Cohort $(\mathrm{N}=18,714)$. Annals of the American Thoracic Society. 2017.

13. Yang P, Sun Z, Krowka MJ, Aubry MC, Bamlet WR, Wampfler JA, et al. Alpha1-antitrypsin deficiency carriers, tobacco smoke, chronic obstructive pulmonary disease, and lung cancer risk. Arch Intern Med 2008;168(10):1097-103.

14. de Torres JP, Bastarrika G, Wisnivesky JP, Alcaide AB, Campo A, Seijo LM, et al. Assessing the relationship between lung cancer risk and emphysema detected on low-dose CT of the chest. Chest 2007;132(6):1932-8.

15. Wilson DO, Weissfeld JL, Fuhrman CR, Fisher SN, Balogh P, Landreneau RJ, et al. The Pittsburgh Lung Screening Study (PLuSS): outcomes within 3 years of a first computed tomography scan. Am J Respir Crit Care Med 2008;178(9):956-61.

16. Kinsey CM, Estepar RSJ, Wei Y, Wasko GR, Christiani DC. Regional emphysema of a non-small cell tumor is associated with larger tumors and decreased survival. Ann Am Thorac Soc 2015;12(8):1197-205.

17. Amos Cl, Xu W, Spitz MR, editors. Is There a Genetic Basis for Lung Cancer Susceptibility? 1999; Berlin, Heidelberg: Springer Berlin Heidelberg.

18. Durham AL, Adcock IM. The relationship between COPD and lung cancer. Lung Cancer. 2015;90(2):121-7.

19. Schwartz AG, Prysak GM, Bock CH, Cote ML. The molecular epidemiology of lung cancer. Carcinogenesis 2007;28(3):507-18.

20. Tran I, Ji C, Ni I, Min T, Tang D, Vij N. Role of Cigarette Smoke-Induced Aggresome Formation in Chronic Obstructive Pulmonary Disease-Emphysema Pathogenesis. Am J Respir Cell Mol Biol. 2015;53(2):159-73.

21. Gould NS, Min E, Gauthier S, Chu HW, Martin R, Day BJ. Aging adversely affects the cigarette smokeinduced glutathione adaptive response in the lung. Am J Respir Crit Care Med 2010;182(9):1114-22.

22. Hoeijmakers JHJ. DNA Damage, Aging, and Cancer. N Engl J Med 2009;361:1475-85. 
23. Phillips DH, Hewer A, Martin CN, Garner RC, King MM. Correlation of DNA adduct levels in human lung with cigarette smoking. Nature 1988;336(22):790-2.

24. Godschalk R, Nair J, Van Schooten FJ, Risch A, Drings P, Kayser K, et al. Comparison of multiple DNA adduct types in tumor adjacent human lung tissue: effect of cigarette smoking. Carcinogenesis 2002;23(12):2081-6.

25. Aoshiba K, Koinuma M, Yokohori N, Nagai A. Immunohistochemical Evaluation of Oxidative Stress in Murine Lungs After Cigarette Smoke Exposure. Inhal Toxicol 2003;15(10):1029-38.

26. Huang YT, Lin X, Liu Y, Chirieac LR, McGovern R, Wain J, et al. Cigarette smoking increases copy number alterations in nonsmall-cell lung cancer. Proc Natl Acad Sci U S A 2011;108(39):16345-50.

27. Alexandrov LB, Ju YS, Haase K, Van Loo P, Martincorena I, Nik-Zainal S, et al. Mutational signatures associated with tobacco smoking in human cancer. Science 2016;354(6312):618-22.

28. Minna JD, Roth JA, Gazdar AF. Focus on Lung Cancer. Cancer Cell 2002;1:49-52.

29. Roos WP, Thomas AD, Kaina B. DNA damage and the balance between survival and death in cancer biology. Nat Rev Cancer 2016;16(1):20-33.

30. Massion PP, Zou Y, Chen $\mathrm{H}$, Jiang A, Coulson $\mathrm{P}$, Amos $\mathrm{Cl}$, et al. Smoking-related genomic signatures in non-small cell lung cancer. Am J Respir Crit Care Med 2008;178(11):1164-72.

31. Park I-W, Wistuba II, Maitra A, Milchgrub S, Virmani AK, Minna JD, et al. Multiple Clonal Abnormalities in the Bronchial Epithelium of Patients with Lung Cancer. J Natl Cancer Inst 1999;91(21):1863-8.

32. Zochbauer-Muller S, Fong KM, Virmani AK, Geradts J, Gazdar AF, Minna JD. Aberrant Promoter Methylation of Multiple Genes in Non-Small Cell Lung Cancers. Cancer Res 2001;61:249-55.

33. Hang B. Formation and repair of tobacco carcinogen-derived bulky DNA adducts. J Nucleic Acids 2010;2010:ID: 709521.

34. Caramori G, Adcock IM, Casolari P, Ito K, Jazrawi E, Tsaprouni L, et al. Unbalanced oxidant-induced DNA damage and repair in COPD: a link towards lung cancer. Thorax 2011;66(6):521-7.

35. Igishi T, Hitsuda Y, Kato K, Sako T, Burioka N, Yasuda K, et al. Elevated urinary 8hydroxydeoxyguanosine, a biomarker of oxidative stress, and lack of association with antioxidant vitamins in chronic obstructive pulmonary disease. Respirology 2003;8:455-60.

36. Deslee G, Woods JC, Moore C, Conradi SH, Gierada DS, Atkinson JJ, et al. Oxidative damage to nucleic acids in severe emphysema. Chest 2009;135(4):965-74.

37. Inoue M, Osaki T, Noguchi M, Hirohashi S, Yasumoto K, Kasai H. Lung Cancer Patients Have Increased 8-Hydroxydeoxyguanosine Levels in Peripheral Lung Tissue DNA. Jpn J Cancer Res 1998;89:691-5.

38. Tzortzaki EG, Dimakou K, Neofytou E, Tsikritsaki K, Samara K, Avgousti M, et al. Oxidative DNA damage and somatic mutations: a link to the molecular pathogenesis of chronic inflammatory airway diseases. Chest 2012;141(5):1243-50.

39. Neofytou E, Tzortzaki EG, Chatziantoniou A, Siafakas NM. DNA damage due to oxidative stress in Chronic Obstructive Pulmonary Disease (COPD). Int J Mol Sci 2012;13(12):16853-64.

40. Ceylan E, Kocyigit A, Gencer M, Aksoy N, Selek S. Increased DNA damage in patients with chronic obstructive pulmonary disease who had once smoked or been exposed to biomass. Respir Med 2006;100(7):1270-6.

41. Aoshiba K, Zhou F, Tsuji T, Nagai A. DNA damage as a molecular link in the pathogenesis of COPD in smokers. Eur Respir J 2012;39(6):1368-76.

42. Zervou MI, Tzortzaki EG, Makris D, Gaga M, Zervas E, Economidou E, et al. Differences in microsatellite DNA level between asthma and chronic obstructive pulmonary disease. Eur Respir $\mathrm{J}$ $2006 ; 28(3): 472-8$.

43. Siafakas NM, Tzortzaki EG, Sourvinos G, Bouros D, Tzanakis N, Kafatos A, et al. Microsatellite DNA Instability in COPD. Chest 1999;116(1):47-51.

44. Samara K, Zervou M, Siafakas NM, Tzortzaki EG. Microsatellite DNA instability in benign lung diseases. Respir Med 2006;100(2):202-11.

45. Pastukh VM, Zhang L, Ruchko MV, Gorodnya O, Bardwell GC, Tuder RM, et al. Oxidative DNA damage in lung tissue from patients with COPD is clustered in functionally significant sequences. Int $\mathrm{J}$ Chron Obstruct Pulmon Dis 2011;6:209-17. 
46. Smolarz B, Romanowicz-Makowska H, Langer E, Kozlowska E, Kulig A, Dziki A. Genetics Analysis of Microsatellite Markers in Patients from Hereditary Nonpolyposis Colorectal Cancer (HNPCC) Family. Exp Oncol 2004;26(3):205-9.

47. Gavande NS, VanderVere-Carozza PS, Hinshaw HD, Jalal SI, Sears CR, Pawelczak KS, et al. DNA repair targeted therapy: The past or future of cancer treatment? Pharmacol Ther 2016;160:65-83.

48. Brennan P, Hainaut P, Boeffetta P. Genetics of lung cancer susceptibility. Lancet Oncol 2011;12:399408.

49. Spitz MR, Wei Q, Dong Q, Amos CI, Wu X. Genetic Susceptibility to Lung Cancer: The Role of DNA Damage and Repair. Cancer Epidemiol Biomarkers Prev 2003;12:689-98.

50. Wood RD, Mitchell M, Sgouros J, Lindahl T. Human DNA Repair Genes. Science $2001 ; 291(5507): 1284-9$.

51. O'Grady S, Finn SP, Cuffe S, Richard DJ, O'Byrne KJ, Barr MP. The role of DNA repair pathways in cisplatin resistant lung cancer. Cancer Treat Rev 2014;40(10):1161-70.

52. Lundholm L, Haag P, Zong D, Juntti T, Mork B, Lewensohn R, et al. Resistance to DNA-damaging treatment in non-small cell lung cancer tumor-initiating cells involves reduced DNA-PK/ATM activation and diminished cell cycle arrest. Cell Death Dis 2013 Jan 31;4:e478.

53. Pastuszak-Lewandoska D, Kordiak J, Antczak A, Migdalska-Sek M, Czarnecka KH, Gorski P, et al. Expression level and methylation status of three tumor suppressor genes, DLEC1, ITGA9 and MLH1, in non-small cell lung cancer. Med Oncol 2016;33(7):75.

54. Lee MN, Tseng RC, Hsu HS, Chen JY, Tzao C, Ho WL, et al. Epigenetic inactivation of the chromosomal stability control genes BRCA1, BRCA2, and XRCC5 in non-small cell lung cancer. Clin Cancer Res 2007;13(3):832-8.

55. Gu C, Lu J, Cui T, Lu C, Shi H, Xu W, et al. Association between MGMT Promoter Methylation and Non-Small Cell Lung Cancer: A Meta-Analysis. PLoS ONE 2013;8(9):e72633.

56. Leng S, Bernauer AM, Hong C, Do KC, Yingling CM, Flores KG, et al. The A/G allele of rs 16906252 predicts for MGMT methylation and is selectively silenced in premalignant lesions from smokers and in lung adenocarcinomas. Clin Cancer Res 2011;17(7):2014-23.

57. Povey AC, Margison GP, Santibanez-Koref MF. Lung cancer risk and variation in MGMT activity and sequence. DNA Repair (Amst) 2007;6(8):1134-44.

58. Paz-Elizur T. DNA Repair Activity for Oxidative Damage and Risk of Lung Cancer. CancerSpectrum Knowledge Environment 2003;95(17):1312-9.

59. Karahalil B, Bohr VA, de Souza-Pinto NC. Base Excision Repair Activities Differ in Human Lung Cancer Cells and Corresponding Normal Controls. Anticancer Res 2010;30:4963-72.

60. Sevilya Z, Leitner-Dagan Y, Pinchev M, Kremer R, Elinger D, Lejbkowicz F, et al. Development of APE1 enzymatic DNA repair assays: low APE1 activity is associated with increase lung cancer risk. Carcinogenesis. 2015;36(9):982-91.

61. Sevilya Z, Leitner-Dagan Y, Pinchev M, Kremer R, Elinger D, Rennert HS, et al. Low integrated DNA repair score and lung cancer risk. Cancer Prev Res (Phila). 2014;7(4):398-406.

62. Dey S, Maiti AK, Hegde ML, Hegde PM, Boldogh I, Sarkar PS, et al. Increased risk of lung cancer associated with a functionally impaired polymorphic variant of the human DNA glycosylase NEIL2. DNA Repair (Amst). 2012;11(6):570-8.

63. Crosbie PA, Watson AJ, Agius R, Barber PV, Margison GP, Povey AC. Elevated N3-methylpurine-DNA glycosylase DNA repair activity is associated with lung cancer. Mutat Res 2012;732(1-2):43-6.

64. Shen H, Spitz MR, Qiao Y, Guo Z, Wang LE, Bosken CH, et al. Smoking, DNA repair capacity and risk of nonsmall cell lung cancer. Int J Cancer 2003;107(1):84-8.

65. Paz-Elizur T, Elinger D, Leitner-Dagan Y, Blumenstein S, Krupsky M, Berrebi A, et al. Development of an enzymatic DNA repair assay for molecular epidemiology studies: distribution of OGG activity in healthy individuals. DNA Repair (Amst). 2007;6(1):45-60.

66. Paz-Elizur T, Krupsky M, Blumenstein S, Elinger D, Schechtman E, Livneh Z. DNA Repair Activity for Oxidative Damage and Risk of Lung Cancer. J Natl Cancer Inst 2003;95(17):1312-9.

67. Wang L, Wei Q, Shi Q, Guo Z, Qiao Y, Spitz MR. A modified host-cell reactivation assay to measure repair of alkylating DNA damage for assessing risk of lung adenocarcinoma. Carcinogenesis $2007 ; 28(7): 1430-6$. 
68. Leitner-Dagan Y, Sevilya Z, Pinchev M, Kramer R, Elinger D, Roisman LC, et al. N-methylpurine DNA glycosylase and OGG1 DNA repair activities: opposite associations with lung cancer risk. J Natl Cancer Inst 2012;104(22):1765-9.

69. Leitner-Dagan Y, Sevilya Z, Pinchev M, Kremer R, Elinger D, Rennert HS, et al. Enzymatic MPG DNA repair assays for two different oxidative DNA lesions reveal associations with increased lung cancer risk. Carcinogenesis 2014;35(12):2763-70.

70. Russo MT, De Luca G, Degan P, Parlanti E, Dogliotti E, Barnes DE, et al. Accumultaion of the Oxidative Base Lesion 8-Hydroxyguanine in DNA of Tumor-Prone Mice Defective in Both the Myh and Ogg1 DNA Glycosylases. Cancer Res 2004;64:4411-4.

71. Xie Y, Yang H, Cunanan C, Okamoto K, Shibata D, Pan J, et al. Deficiencies in Mouse Myh and Ogg1 Result in Tumor Predisposition and G to T Mutations in Codon 12 of the K-Ras Oncogene in Lung Tumors. Cancer Res 2004;64:3096-102.

72. Sakumi K, Tominaga Y, Furuichi M, Xu P, Tsuzuki T, Sekiguchi M, et al. Ogg1 knockout-associated lung tumorigenesis and its suppression by Mth1 gene disruption. Cancer Res 2003;63(5):902-5.

73. Wu Z, Lin Y, Xu H, Dai H, Zhou M, Tsao S, et al. High risk of benzo[alpha]pyrene-induced lung cancer in E160D FEN1 mutant mice. Mutat Res 2012;731(1-2):85-91.

74. Wang Y, Xu Z, Mao JH, Hsieh D, Au A, Jablons DM, et al. PR-Set7 is Degraded in a Conditional Cul4A Transgenic Mouse Model of Lung Cancer. Zhongguo Fei Ai Za Zhi 2015;18(6):345-50.

75. Wang Y, Xu Z, Mao JH, Hung MS, Hsieh D, Au A, et al. Analysis of lung tumor initiation and progression in transgenic mice for $\mathrm{Cre}$-inducible overexpression of Cul4A gene. Thorac Cancer 2015;6(4):480-7.

76. Melis JP, Wijnhoven SW, Beems RB, Roodbergen M, van den Berg J, Moon H, et al. Mouse models for xeroderma pigmentosum group $\mathrm{A}$ and group $\mathrm{C}$ show divergent cancer phenotypes. Cancer Res 2008;68(5):1347-53.

77. Hollander MC, Philburn RT, Patterson AD, Velasco-Miguel S, Friedberg EC, Linnoila RI, et al. Deletion of XPC leads to lung tumors in mice and is associated with early events in human lung carcinogenesis. Proc Natl Acad Sci U S A 2005;102(37):13200-5.

78. Friedberg EC, Bond JP, Burns DK, Cheo DL, Greenblatt MS, Meira LB, et al. Defective nucleotide excision repair in XPC mutant mice and its association with cancer predisposition. Mutat Res 2000;459:99-108.

79. Houghtaling S, Granville L, Akkari Y, Torimaru Y, Olson S, Finegold M, et al. Heterozygosity for p53 (Trp53+/-) accelerates epithelial tumor formation in fanconi anemia complementation group D2 (Fancd2) knockout mice. Cancer Res 2005;65(1):85-91.

80. Zhang X, He N, Gu D, Wickliffe J, Salazar J, Boldogh I, et al. Genetic Evidence for XPC-KRAS Interactions During Lung Cancer Development. Journal of Genetics and Genomics. 2015;42:589-96.

81. Downey CM, Jirik FR. DNA mismatch repair deficiency accelerates lung neoplasm development in Kras(LA1/+) mice: a brief report. Cancer Med 2015;4(6):897-902.

82. Jokic M, Vlasic I, Rinneburger M, Klumper N, Spiro J, Vogel W, et al. Ercc1 Deficiency Promotes Tumorigenesis and Increases Cisplatin Sensitivity in a Tp53 Context-Specific Manner. Mol Cancer Res 2016;14(11):1110-23.

83. Ramdzan ZM, Vadnais C, Pal R, Vandal G, Cadieux C, Leduy L, et al. RAS transformation requires CUX1-dependent repair of oxidative DNA damage. PLoS Biol 2014;12(3):e1001807.

84. Caramori G, Casolari P, Cavallesco GN, Giuffre S, Adcock I, Papi A. Mechanisms involved in lung cancer development in COPD. The International J Biochem Cell Biol 2011;43(7):1030-44.

85. de Andrade M, Li Y, Marks RS, Deschamps C, Scanlon PD, Olswold CL, et al. Genetic variants associated with the risk of chronic obstructive pulmonary disease with and without lung cancer. Cancer Prev Res (Phila) 2012;5(3):365-73.

86. da Silva ALG, da Rosa HT, Karnopp TE, Charlier CF, Ellwanger JH, Moura DJ, et al. Evaluation of DNA damage in COPD patients and its correlation with polymorphisms in repair genes. BMC Med Genet 2013;14:93.

87. Sears CR, Zhou H, Justice MJ, Fisher AJ, Saliba J, Lamb I, et al. Xeroderma Pigmentosum Group C Deficiency Alters Cigarette Smoke DNA Damage Cell Fate and Accelerates Emphysema Development. Am J Respir Cell Mol Biol 2018;58(3):402-11. 
88. Hersh CP, Pillai SG, Zhu G, Lomas DA, Bakke P, Gulsvik A, et al. Multistudy fine mapping of chromosome $2 q$ identifies XRCC5 as a chronic obstructive pulmonary disease susceptibility gene. Am J Respir Crit Care Med 2010;182(5):605-13.

89. Tseng RC, Hsieh FJ, Shih CM, Hsu HS, Chen CY, Wang YC. Lung cancer susceptibility and prognosis associated with polymorphisms in the nonhomologous end-joining pathway genes: a multiple genotypephenotype study. Cancer 2009;115(13):2939-48.

90. Yeo J, Morales DA, Chen T, Crawford EL, Zhang X, Blomquist TM, et al. RNAseq analysis of bronchial epithelial cells to identify COPD-associated genes and SNPs. BMC Pulmonary Medicine 2018;18(1):42.

91. Korytina GF, Akhmadishina LZ, Kochetova OV, Burdiuk lu V, Aznabaeva lu G, Zagidullin Sh Z, et al. [Association of the nicotine and cigarette smoke toxicants metabolic (CHRNA3/5, CYP2A6, NQO1) and DNA repair genes (XRCC1, XRCC3, XPC, XPA) with chronic obstructive pulmonary disease]. Mol Biol (Mosk) 2014;48(6):939-51.

92. Hung RJ, Hall J, Brennan P, Boffetta P. Genetic polymorphisms in the base excision repair pathway and cancer risk: a HuGE review. Am J Epidemiol 2005;162(10):925-42.

93. Vogel H, Lim D-S, Karsenty G, Finegold M, Hasty P. Deletion of Ku86 causes early onset of senescence in mice. Proc Natl Acad Sci U S A 1999;96:10770-5.

94. Matsuyama S, Palmer J, Bates A, Poventud-Fuentes I, Wong K, Ngo J, et al. Bax-induced apoptosis shortens the life span of DNA repair defect Ku70-knockout mice by inducing emphysema. Exp Biol Med (Maywood) 2016;241(12):1265-71.

95. Oit-Wiscombe I, Virag L, Soomets U, Altraja A. Increased DNA Damage in Progression of COPD: A Response By Poly(ADP-Ribose) Polymerase-1. PLoS ONE 2013;8(7):e70333.

96. Spandidos D, Ergazaki M, Hatzistamou J, Kiaris H, Bouros D, Tzortzaki E, et al. Microsatellite instability in patients with chronic obstructive pulmonary disease. Oncol Rep 1996;3(3):489-91.

97. Cooper WA, Kohonen-Corish MR, Chan C, Kwun SY, McCaughan B, Kennedy C, et al. Prognostic significance of DNA repair proteins MLH1, MSH2 and MGMT expression in non-small-cell lung cancer and precursor lesions. Histopathology 2008;52(5):613-22.

98. Ma Y, Chen Y, Petersen I. Expression and promoter DNA methylation of MLH1 in colorectal cancer and lung cancer. Pathol Res Pract 2017;213(4):333-8.

99. Li M, Zhang Q, Liu L, Lu W, Wei H, Li RW, et al. Expression of the mismatch repair gene hMLH1 is enhanced in non-small cell lung cancer with EGFR mutations. PLoS One 2013;8(10):e78500.

100. Zabarovsky ER, Lerman MI, Minna JD. Tumor suppressor genes on chromosome $3 p$ involved in the pathogenesis of lung and other cancers. Oncogene 2002;21:6915-35.

101. Hung J, Kishimoto Y, Sugio K, Virmani A, McIntire DD, Minna JD, et al. Allele-Specific Chromosome 3p Deletions Occur at an Early Stage in the Pathogenesis of Lung Cancrinoma. JAMA 1995;273(7):55863.

102. Menoni $\mathrm{H}$, Hoeijmakers $\mathrm{JH}$, Vermeulen W. Nucleotide excision repair-initiating proteins bind to oxidative DNA lesions in vivo. J Cell Biol 2012;199(7):1037-46.

103. Melis JP, Kuiper RV, Zwart E, Robinson J, Pennings JL, van Oostrom CT, et al. Slow accumulation of mutations in Xpc mice upon induction of oxidative stress. DNA Repair 2013;12:1081-6.

104. Melis JP, Luijten M, Mullenders LH, van Steeg H. The role of XPC: implications in cancer and oxidative DNA damage. Mutat Res 2011;728(3):107-17.

105. Parlanti E, D'Errico M, Degan P, Calcagnile A, Zijno A, van der Pluijm I, et al. The cross talk between pathways in the repair of 8-oxo-7,8-dihydroguanine in mouse and human cells. Free Radic Biol Med 2012;53(11):2171-7.

106. Stearman RS, Dwyer-Nield L, Zerbe L, Blaine SA, Chan Z, Bunn PA, et al. Analysis of Orthologous Gene Expression between Human Pulmonary Adenocarcinoma and a Carcinogen-Induced Murine Model. Am J Pathol 2005;167(6):1763-75.

107. de Feraudy S, Ridd K, Richards LM, Kwok PY, Revet I, Oh D, et al. The DNA damage-binding protein $\mathrm{XPC}$ is a frequent target for inactivation in squamous cell carcinomas. Am J Pathol 2010;177(2):555-62.

108. Jin B, Dong Y, Zhang X, Wang H, Han B. Association of XPC Polymorphisms and Lung Cancer Risk: A Meta-Analysis. PLoS ONE 2014;9(4):e93937.

109. Francisco G, Menezes PR, Eluf-Neto J, Chammas R. XPC polymorphisms play a role in tissue-specific carcinogenesis: a meta-analysis. Eur J Hum Genet 2008;16(6):724-34. 
110. Marin MS, Lopez-Cima MF, Garcia-Castro L, Pascual T, Marron MG, Tardon A. Poly (AT) Polymorphism in Intron 11 of the XPC DNA Repair Gene Enhances the Risk of Lung Cancer. Cancer Epidemiol Biomarkers Prev 2004;13:1788-93.

111. Lee H-W, Wang H-T, Weng M-w, Chin C, Huang W, Lepor H, et al. Cigarette side-stream smoke lung and bladder carcinogenesis: Inducing mutagenic acrolein-DNA adducts, inhibiting DNA repair and enhancing anchorage-independence-growth cell transformation. Oncotarget 2015;6(32):33226-36.

112. DiGiovanna JJ, Kraemer KH. Shining a light on xeroderma pigmentosum. J Investig Dermatol 2012;132(3 Pt 2):785-96.

113. Witschi H, Espiritu I, Peake JL, Wu K, Maronpot RR, Pinkerton KE. The carcinogenicity of environmental tobacco smoke. Carcinogenesis 1997;18(3):575-86. 
Table 1: Proposed DNA repair proteins in lung cancer and COPD/emphysema

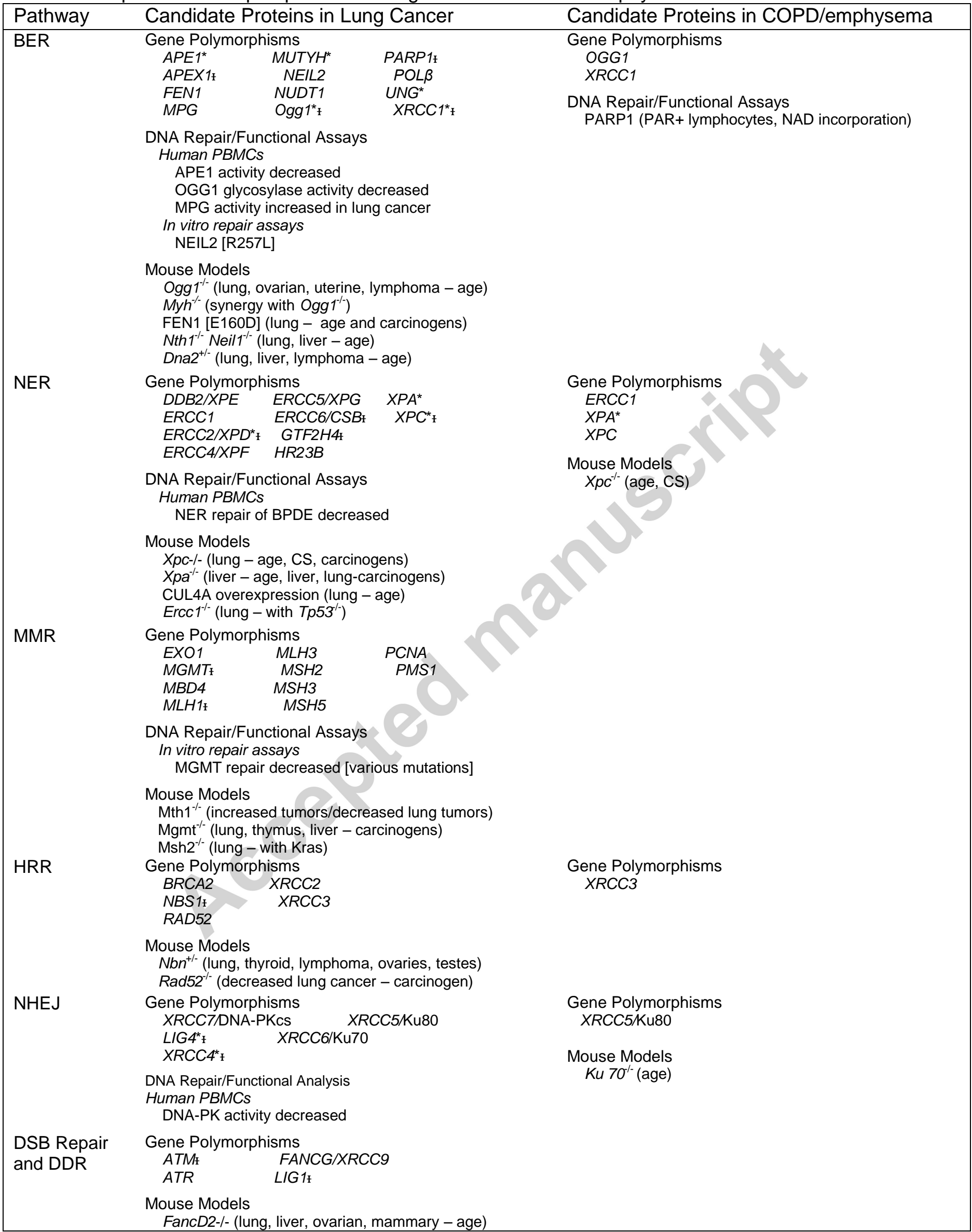


* Synergy observed with other DNA repair protein variants or functional variants. $¥$ Risk may be altered by cigarette smoking status. Bold indicates those proteins in which certain SNPs appear to increase lung cancer or emphysema risk, while others decrease the risk.

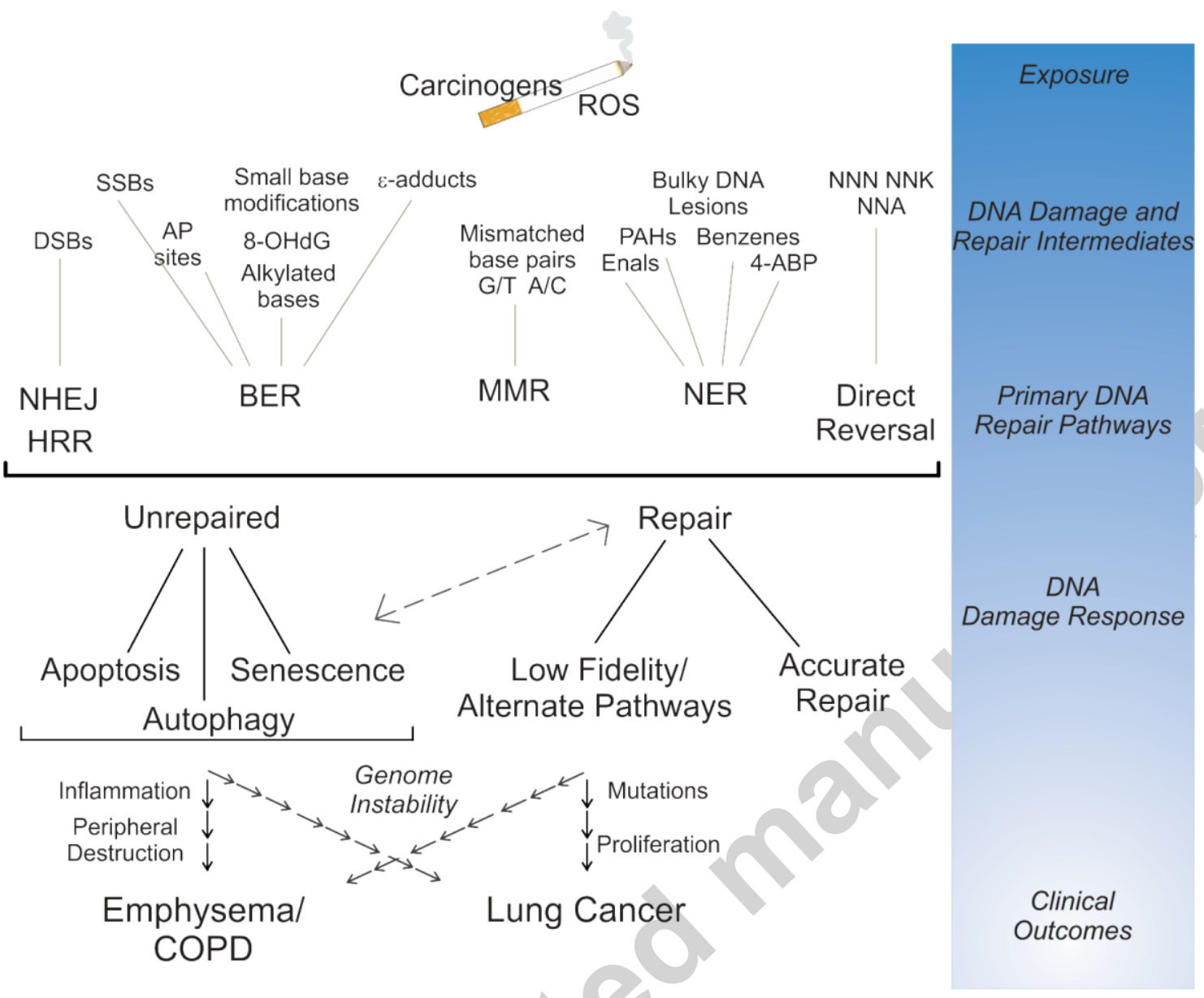

Figure 1: Schematic presentation of the formation, repair, and subsequent cellular and biological effects of tobacco smoking-induced damage to genomic DNA. The DNA damage response elicited by unrepaired lesions, leading to apoptosis, autophagy, and/or senescence and low fidelity repair pathways may play an important role in the development of genome instability and ultimately, both COPD/emphysema and lung cancer. DSBs: double strand DNA breaks, NNA: 4-(methylnitrosamino)-4-(3-pyridyl)butanal, NNK: 4(methylnitrosamino)-1-(3-pyridyl)-1-butanone, NNN: N'-nitrosonornicotine, PAH: polycyclic aromatic hydrocarbon, ROS: reactive oxygen species, SSBs: single strand DNA breaks. 